\title{
Editorial
}

\section{News from the "Cercle Français des Microscopies à Champ \\ Proche" (CFMCP)}

As a continuation of volume IV, number 5, october 1993, the present issue of Microscopy, Microanalysis, Microstructures is also devoted to the publication of the Proceedings of the two days symposium on Near Field Microscopies which took place in Lyon on June 30 and July 1, 1993, during the annual meeting of the SFME. The papers gathered in this volume cover various aspects ranging from new instrumentation to applications in physics as well as in biology.

As announced in the previous editorial, we wish to maintain the fruitful reflexion and exchanges initiated during the previous meetings organized by the CNRS GdR and with the support of the Ultimatech interdisciplinary program.

The next meeting will therefore take place in Aix-en-Provence on July 4 to 6, 1994. Heinrich Rohrer, from IBM Zürich laboratories, will open this three days meeting with a personal survey on chances and challenges in nanoscience and nanotechnology. Stimulating invited talks on the latest developments in physics and biology are also planned for this opening session.

For anyone interested to get more information about the organization of this meeting, please contact F. Salvan in Luminy.

We also wish to remind you that the scientific program of ICEM 13 in Paris from 17 to 22 July incorporates several symposia of interest for the community of Near-Field microscopists: NearField Microscopy; Clusters, nanoparticles, fullerenes and related structures; Surface structures; Surface reactivity; New microscopies in biology.... They will offer an enlarged forum for the comparison of different technical approaches on the same object.

The editorial board of CFMCP

J. Beauvillain, CEMES-LOE, CNRS, Toulouse

L. Porte, Ecole Centrale, Ecully

F. Salvan, GPEC, Luminy 